\title{
Visualizing the sequential process of knowledge elaboration in computer-supported collaborative problem solving
}

\author{
N. Ding * \\ Faculty of Behavioral and Social Sciences, University of Groningen, P.O. Box 1286, 9701 BG Groningen, The Netherlands
}

\section{A R T I C L E I N F O}

Article history:

Received 15 November 2007

Received in revised form 10 October 2008

Accepted 14 October 2008

\section{Keywords:}

Computer-mediated communication

Cooperative/collaborative learning

Secondary education

Gender studies

\begin{abstract}
A B S T R A C T
This case study illustrates the sequential process of the joint and individual knowledge elaboration in a computer-supported collaborative learning (CSCL) environment. The case comprised an Internet-based physics problem-solving platform. Six Dutch secondary school students (three males, three females) participated in the three-week experiment. They were paired based on self-selection. Each dyad was asked to collaborate on eight moderately structured problems concerning Newtonian mechanics. Their online interactions, including their textual and pictorial messages, were categorized and sequentially plotted. The three dyads showed three different collaboration patterns in terms of joint and individual knowledge elaboration.
\end{abstract}

(c) 2008 Elsevier Ltd. All rights reserved.

\section{Introduction}

Research on collaborative learning has demonstrated better cognitive development for students than for those learning individually (Cohen, 1994; Dillenbourg, 1999; Johnson \& Johnson, 1994). Collaborative problem solving is a coordinated and synchronous activity within which individuals attempt to solve the problem through reflection, negotiation, correction and co-construction of meanings (Roschelle \& Teasley, 1995; Van Boxtel, 2000; Webb \& Farivar, 1999). With respect to knowledge elaboration, collaborative problem solving appears to be a promising heuristic task (Heller, Keith, \& Anderson, 1992; Lehtinen, 2003; Nelson, 1999; Teasley, 1995). Our study stems from the elaboration perspective, which stresses the presence of detailed clarifications such as highly elaborated arguments. In our previous studies, we found that group composition had a significant influence on female students' representation format, communication content and problem-solving foci in the collaborative learning process. What is still unclear is the precise nature of the students' knowledge elaboration process in computer-supported collaborative learning (CSCL). Therefore, we have embarked on this case study which focused on three dyad's online collaboration while solving physics problems. After analyzing the students' verbal and visual interactions extensively, we found that three individual knowledge elaboration patterns emerged. In the sections that follow, we will first delineate the theoretical framework behind collaborative learning, which is the basis of the current study. Then we will discuss the specific features of a computer-supported learning environment in terms of joint and individual knowledge elaboration. Following this, we will give a brief account of the computer program "PhysHint", used in solving physics problems, and how it was applied. Subsequently, we will deliberate on three case examples in order to explore joint and individual knowledge elaboration. Finally, the implications for future research will be examined.

\section{Joint and individual knowledge elaboration}

In collaborative learning the group is the learning agent (Suthers, 2006). Heller et al. (1992) concluded that group problem solutions were far better than those produced by the individual problem-solver. Many conceptual difficulties are quickly and clearly addressed by peer learners. The group problem-solving process can be regarded as a joint process of knowledge elaboration, which is made up of numerous meaningful artifacts, such as utterances, visual representations, gestures, and facial expressions used in face-to-face collaboration.

\footnotetext{
* Fax: +31 503636670 .

E-mail address: n.ding@rug.nl
} 
Elaboration of knowledge is the key factor for students' effective problem solving and in how they learn scientific concepts (De Jong \& Ferguson-Hessler, 1993; van Boxtel, 2000). To solve a problem collaboratively, highly elaborative messages are not only important for group success, but also for knowledge acquisition and expansion of the individual learner. There is much research that shows that, working in the collaboration, students' learning is closely correlated with the elaborative explanations instead of simple forms of exchanges (Lemke, 1999; Van der Meijden \& Veenman, 2005; Webb \& Farivar, 1999). However, students do not spontaneously generate highly elaborate explanations or questions (King, 1999).

Collaborative learning involves the individual's cognitive elaboration and does not reduce it (Stahl, Koschmann, \& Suthers, 2006). During collaboration there are some qualitative differences in the individual's involvement. Each person has his/her uniquely situated prior knowledge and pre-understanding. Knowledge elaboration in collaboration may differ across participants, and each individual may vary in terms of his/her degree of contribution and engagement.

Based on previous research and experimental studies, we found several mechanisms that were essential for knowledge elaboration during collaboration. In research on what elaborative collaboration is, Sizmur and Osborne (1997) differentiated non-elaborated exchanges that are not constructed by other participants from elaborated exchanges that are extended and deepened on the basis of participants' previous exchanges. They further differentiated individually elaborated exchanges from collaboratively elaborated exchanges. Erkens (1997) looked into the extent of students' interaction and investigated whether students shared ideas and understandings with their peers. Kumpulainen and Mutanen (1999) distinguished three cognitive processing modes: procedural processing, interpretative or exploratory processing and an off-task activity mode. Van Boxtel (2004) postulated that elaboration takes place when students used the examples, analogies, and experiences to create new relationships. Cohen (1994) pointed out the importance of understanding the mechanisms that support or inhibit learning in group interaction. Based on these research findings, we found that cognitive difference and subsequent clarification were the most important mechanisms contributing to a productive collaboration (Baker, 1999; Suthers, 2006; Van der Meijden et al., 2005). To resolve the conflict, students may offer an explanation, argue or negotiate with each other (Brown \& Palincsar, 1989; Dillenbourg, Baker, Blay \& O'Malley, 1995). However, some studies have shown that students often try to avoid conflict partly because of the existence of a dominant role in the group, which results partly from the social pressure entailed challenging others (Webb, 1995).

After conflict emerges, an explanation then seems necessary. This helps students explicate their thinking processes and bridge the knowledge gap (Hertz-Lazarowitz, 1992). While explicating the thinking process, students can reflect, correct, restructure, and expand their knowledge, and thereby promote their conceptual understanding (King, 1999; Van Boxtel, 2000; Webb \& Farivar, 1999). The burden of explanation pushes the students to evaluate, integrate and elaborate knowledge in new ways (Van Boxtel, 2000).

Furthermore, if there is a disagreement, elaborative argumentation takes on equal importance. Arguing with a peer learner means both participants share a focus on the same issue, assess information for its relevance and map knowledge to form a sound argument. But sometimes so-called "face saving" may result in a blind acceptance of any solution including those that inhibit the argumentation.

Another way to resolve the conflict is through negotiation. Negotiation facilitates an awareness of shared goals (Dillenbourg, 1999). However, it has been found that learners tend to avoid negotiation as well (Chang, Sung, \& Lee, 2003).

These mechanisms depict an ideal form of elaborative collaboration from which both the group and individuals may profit. Nevertheless, both joint and individual knowledge elaboration may present a somewhat different picture in a computer-supported learning environment. In the next section, we will discuss several features of knowledge elaboration in CSCL.

\section{Knowledge elaboration in CSCL}

In the computer-mediated learning environment that our study is mainly concerned with, verbal and visual representations in student interactions are of ultimate importance for the joint knowledge elaboration of students. The interactive feature of CSCL facilitates the students' self-consciousness about misconceptions and the gap in knowledge between peer learners, as well as their modification of prior knowledge that might lie beyond their repertoire (Miyake, 2006). Previous CSCL studies, however, have indicated a high proportion of task-unrelated exchanges that hamper knowledge elaboration (De Corte, Verschaffel, Entwistle, \& Van Merriënboer, 2003; Howe, Tolmie, Duchak-Tanner, \& Rattray, 2000). The following reasons may help explain some of this.

First of all, the lack of co-present cues in the synchronous CSCL may influence students' communication. Learners have no access to facial expressions, body language, and tone of voice. A substantial amount of incoherent communication is to be expected as a result.

Secondly, shared contextual cues are reduced, leading to a controversial effect on students' knowledge elaboration. On the one hand, reduced shared context is expected to bring about a reduction in utility (Suthers, 2006). For instance, participants have the difficulty in using deictic reference. Instead of saying "that one" or "this one" they have to describe the referent explicitly. It can be assumed that the explanations may then appear in a simple form, while the negotiation may end up being less effective than it would be in face-to-face collaboration. On the other hand, in a face-to-face setting the presence of other people can inhibit the participant's performances due to fear of failure (Dix, Finlay, Abowd, \& Beale, 1998). It may then be predicted that participants will be able to focus their attention on the task in online collaboration with a dearth of social distractions. Moreover, the visible and preservable talk that is transitory in a face-to-face setting may serve to deepen students' thinking and facilitate a higher level of elaboration. Text-based communication loses most of the low-level feedback of face-to-face conversation (Dix et al., 1998). So we may expect better elaborative interaction with explicit back-references and a greater free-flow of ideas in CSCL talk.

This study is part of a large research project concerning the gender difference in knowledge elaboration within a CSCL environment. Our previous studies used the Bales' IPA model and Schoenfeld's five problem-solving episodes to investigate the effect of partner gender on students' problem solving learning. It was found that female students behaved differently in mixed-gender and same-gender dyads. But this knowledge seemed insufficient to explain how the mixed-gender collaboration disadvantaged female students in science problem solving, especially in terms of how female students deviated from joint knowledge elaboration over time (Ding \& Harskamp, 2006; Harskamp \& Ding, 2006). Moreover, measuring the frequencies or categorizing students' exchanges is inadequate in CSCL research; this is because both of these methods ignore how contextual information influences the individual response. Brown \& Palincsar (1989) pointed out the necessity of a "fine-grained" analysis in order to understand the process of collaborative learning. A process-oriented approach is, therefore, necessary to examine the process of collaboration (Dillenbourg, Baker, Blay, \& O’Malley, 1995). The present study seeks to trace 
the process of joint and individual knowledge elaboration during problem solving and to uncover the difference in elaborative work between collaborating individuals.

\section{Materials and methods}

This study is a descriptive study focusing on an in-depth understanding of the interaction between the selected cases. Admittedly, the individualistic features of the cases unavoidably destroy the representativeness and the findings are inadequately generalized to the gender research.

The rationale to analyze students' knowledge elaboration is based on the following assumptions:

- Joint knowledge elaboration can be reflected in the content of dyadic interactions.

- Individual knowledge elaboration can be reflected in the content of individual communicative representations.

- No piece of communicative representation exists in isolation, but is embedded in a context.

\subsection{Elaboration value}

As stated in knowledge-building pedagogy, ideas can be improved. The problem-solving task is a goal-oriented task. To solve the problem, students communicate with each other to accomplish a set of goals and sub-goals. Thus, the messages they exchange could well be interpreted as stepping stones directed toward goals. Analysis should serve to describe and discern that behavior which is related to goal achievement. If we define the first message that students exchange as the initial state and the subsequent one as meaningfully interrelated to it, we can then plot the track of joint and individual contributions with the help of a sequential analysis of collaboration.

We have used the sequential analysis that acknowledges that the message is a function of its context. In order to quantify each message so as to be able to plot the sum along the timeline, we analyzed the content of each message and endowed each with a number, $-1,0$, or +1 . This was roughly in line with Kumpulainen and Mutanen's (1999) three cognitive processing modes. They acknowledged that procedural processing referred to the routine execution of a task without improving on the ideas. Interpretative or exploratory processing referred to students' deep engagement in a problem solving activity, while off-task activity referred to absent-minded activities or off-task social talk. The differences between Kumpulainen et al.'s modes and our elaboration values are, first, that we have acknowledged the importance of elaborative questions. An elaborative question not only keeps the joint collaboration on the right track, but it also improves individual understanding. Therefore, not only is the interpretative or exploratory processing endowed with a +1 point, but so is the elaborative question. Secondly, our study has focused on a computer-mediated synchronous learning environment with a dearth of shared social context. As mentioned previously, a large number of incoherences have been found in CSCL interactions. Therefore, when we evaluated each message, we did not merely relate it to the previous message, but to the whole context.

Given the transcript below which is related to the space explorer problem shown in Table 2, we went about identifying each message to see how it was related to the final solution of the problem (Table 1 ).

If the message was off-task and distracted the students' attention while problem solving, it was given minus one ( -1$)$. If it was a taskrelated message but did not advance the solving process, it was given zero (0). The presence of a great deal of messages that were 0 -valued would indicate that the students communicated sufficiently, but cognitively they stopped at a certain level. This serves to distinguish between the superficial and the elaborative talk in collaboration. When a message was pertinent to the task of problem solving and was contributive to the final success in problem solving, it was endowed with a one (+1). We aggregated the values of each message and plotted the sum according to the time sequence (see the example in Fig. 3). The next step was to distinguish the individual roles in problem solving. For each individual, we added up the numbers one after another and plotted the sum sequentially (see the example in Fig. 4).

A general picture of joint and individual knowledge elaboration should giver some insight into elaboration in a computer-mediated synchronous problem-solving setting. In the remainder of this article, we will exemplify the analysis of the process of knowledge elaboration using this method. We will look in detail at the collaboration of the three dyads' in the space explorer task, which was the second problem that they worked on.

\subsection{PhysHint: computer-supported collaborative problem solving environment}

The computer program "PhysHint" designed by the authors aims at improving students' problem-solving skills in moderately structured physics problems. It was compiled with SQL to facilitate a synchronous online collaboration. Technically, it can enable 100 dyads to work on the problems at the same time. There are five sections in the PhysHint interface, as shown in Fig. 1.

The problem section shows the problem information. The problem could not been read until both partners logged into the system. Doing this prevented one student from having more time to read and think about the problem than his/her partner (see the sample of the problem in Table 2). In this experiment, eight physics problems in the database were used. Four problems (Problems $2,3,6$, and 8 ) had only one question, while Problems 1, 4, 5, and 7 included two sub-questions.

Table 1

Elaboration values.

\begin{tabular}{|c|c|c|}
\hline Number & Description & Example \\
\hline+1 & Messages elaborating on knowledge and contributing to the final solution & $\begin{array}{l}\text { Student A: What is Newton's 2nd law? } \\
\text { Student } \mathrm{B}: \mathrm{F}=\mathrm{m} * \mathrm{a}\end{array}$ \\
\hline 0 & Messages remaining on the previous elaboration level & $\begin{array}{l}\text { (Student } \mathrm{B}: \mathrm{F}=\mathrm{m} * \mathrm{a} \text { ) } \\
\text { Student A: Yeah }\end{array}$ \\
\hline-1 & Messages that are irrelevant to the task and distract from the problem-solving task & Student B: You'll be going to Rome, won't you? \\
\hline
\end{tabular}




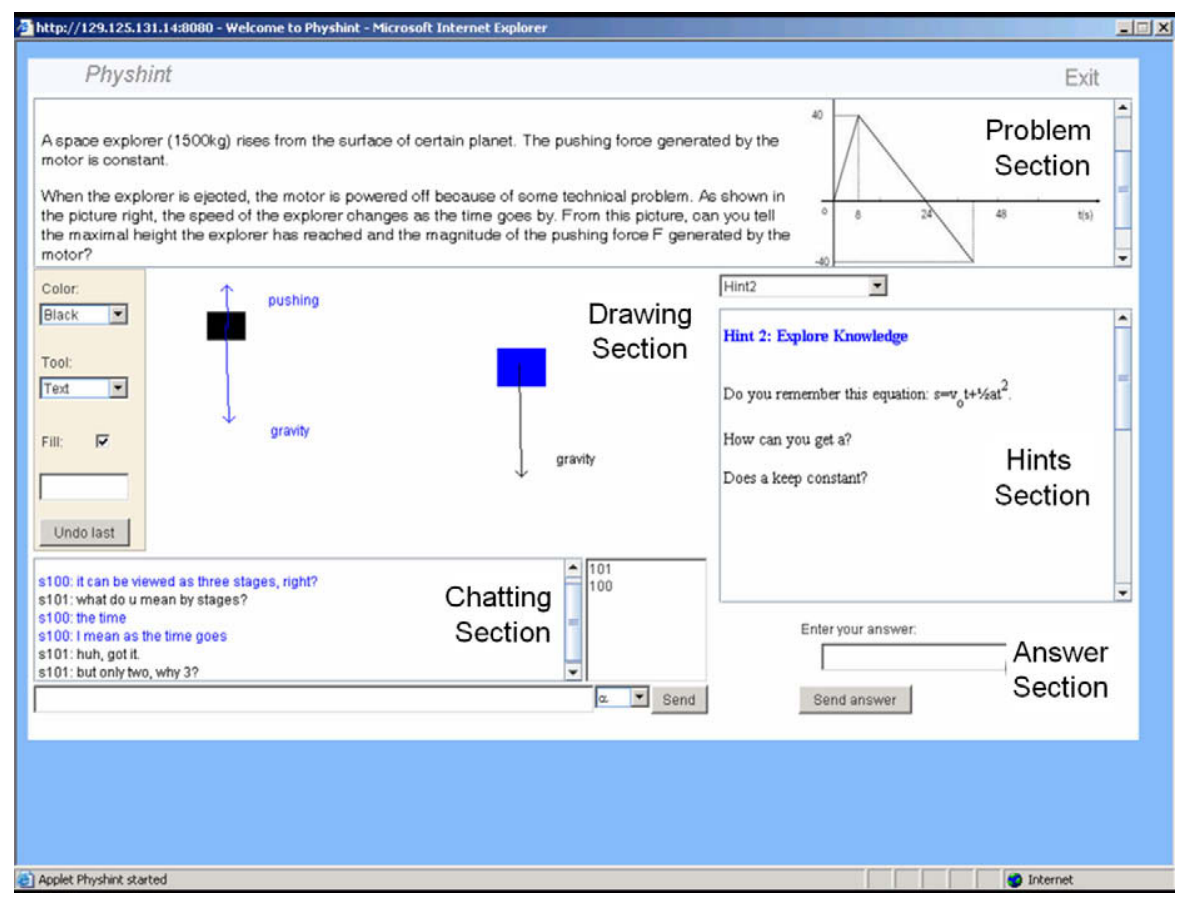

Fig. 1. Interface of PhysHint.

Table 2

Sample problem in the case study.

A space explorer $(1500 \mathrm{~kg}$ ) rises from the surface of a certain planet. The pushing force generated by the motor is constant. When the explorer is ejected, the motor is powered off because of some technical problem. As shown in the picture on the right, the speed of the explorer changes as the time passes. From this picture, can you tell the maximum height the explorer has reached and the magnitude of the pushing force $\mathrm{F}$ generated by the motor?

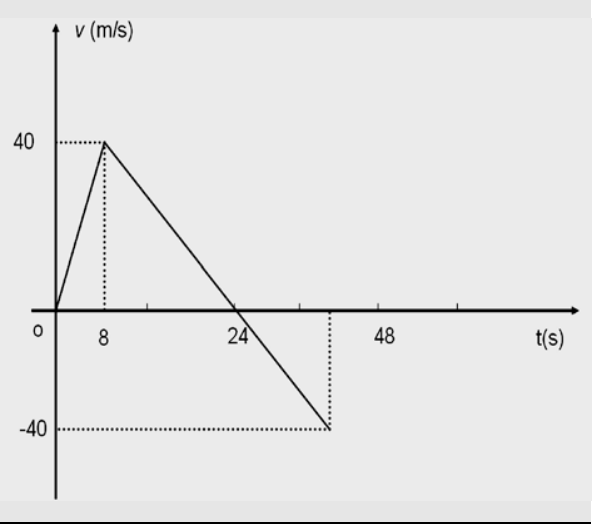

Table 3

Sample of hints.

Student A:

Hint 1: How many periods has the space explorer experienced? What are the initial speeds and resulting force?

Hint 2: Did you remember Newton's Second Law? What is the relationship between the mass and the acceleration?

Hint 3: First start from period $0-8 \mathrm{~s}$, then you can find the acceleration. After that, go on to calculate the gravity acceleration and gravity in period 8-24 s Hint 4: Maybe you arrived at this number: $7500 \mathrm{~N}$

Hint 5: Do you have a better solution?

\section{Student B:}

Hint 1: Read the problem and you will find that the explorer has experienced several periods. In each period, the initial speeds and resulting forces were different. Please list them.

Hint 2: Do you remember this equation: $s=v_{0} t+1 / 2 a t^{2}$. How can you get a? Does a stay constant?

Hint 3: The acceleration in period $0-8 \mathrm{~s}$ is the acceleration due to the resulting force, while the acceleration in period $8-24 \mathrm{~s}$ is the one due to gravity

Hint 4: Maybe you arrived at this number: $16 \mathrm{~s}$

Hint 5: Do you agree with your partner?

The hints section offered each student five "hints" for each problem. All the hints were compiled on the basis of Schoenfeld's five episodes of problem solving (reading the problem, recalling prior knowledge, making a plan, implementing the plan, reflecting on the answers). To strengthen students' communication we gave different students within the same dyad different hints so that they had to engage in exchanges about what they read (see the sample of hints in Table 3). 
Table 4

Sample of worked-out example.

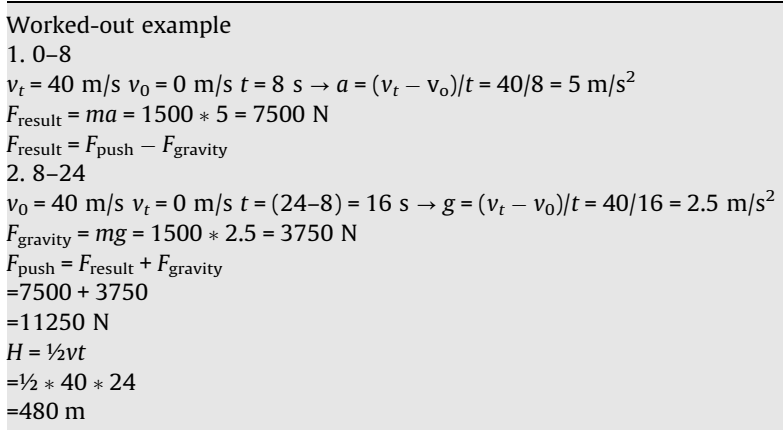

In the drawing section, students were able to draw the variables and vectors using geometric forms, arrows and lines. They could also illustrate the objects with different colors. What one student drew would be automatically shown on his/her partner's computer. The chatting section resembled the MSN Messenger or Yahoo Messenger that students were familiar with. In the texts shown we used different colors (black and blue) to distinguish between the two students in the same dyad. After the students arrived at the answer, they submitted this answer using the answer section. The final submission of the answer was based on mutual agreement of the dyad. For each problem each dyad had two chances to submit an answer. The second time they failed to give a correct answer, a pop-up window with a "worked-out example" (Table 4) was generated.

\subsection{Participants and procedure}

Six tenth graders (three females and three males) from a Dutch secondary school (VWO) participated in the five-day experiment in June, 2006. According to the students' term-examination scores, we limited our scope to average students who received 6 or 7 points in physics exams (10 is the highest grade in the Dutch education system). Before the experiment the students knew each other very well. There were three dyads: a mixed-gender dyad, a female-female dyad, and a male-male dyad. The dyads were assigned to different periods of the day.

Prior to the experiment, each dyad was given a 20-min pre-flight training session and a sample problem in order to learn how to use the PhysHint. On each day they were asked to solve one or two moderately structured physics problems within one and a half hours. Each participant was provided with a desktop computer with the Internet connection. In the experiment students were assigned to different rooms to avoid talk or eye-contact. The entire experiment was overseen by the researchers.

\section{Case studies}

\subsection{Implementation of the study}

During the experiment, the three dyads worked on eight problems. They all failed the first question. The male-male dyad (Henry and Peter) succeeded in solving Problems 3, 4, 5a, 6, and 8; the female-female dyad (Sandy and Carol) succeeded in solving Problems 4, 5, 6, 7, and 8; the mixed-gender (Jenny and Ralf) succeeded in solving Problems 2, 3, 4, 5, 6, 7, and 8. All the participants have been pseudonymous.

\subsubsection{The male-male dyad: Henry and Peter}

Henry and Peter were the two male students. Their physics scores in the school exam were 7.4 and 7.5, respectively. At the beginning of each session they liked to start by exchanging a few short greetings or emotions with each other before reading the problems. Examining their messages, we found a high proportion of task-unrelated messages. They produced the most drawing messages, but $43 \%$ of their drawing messages were task-unrelated In addition, compared with the other dyads, Henry and Peter spent the least time on reading the workedout example.

\subsubsection{The female-female dyad: Sandy and Carol}

In their school exam, both Sandy and Carol scored 7.5 points in physics. They spent around 30 min on each problem, generated the least off-task messages and always finished the problems earlier than the regulated experiment time. We also noticed that at the beginning of each problem, Sandy and Carol spent a lot of time reading the problem information before communication. After finishing the problem, the girls went on to read the worked-out example, spending more time at this than the other dyads did. This dyad produced the least number of visual messages, only $2 \%$ of their messages were visual.

\subsubsection{The mixed-gender dyad: Ralf and Jenny}

In their school exam Ralf had received 7.8 points while Jenny scored 7.6, so there was no substantial difference in their prior knowledge of Newtonian mechanics. During the experiment, Ralf and Jenny solved seven out of eight problems. In each experiment session they were the ones who spent the most time on problem solving. They also exchanged the most messages. Sometimes when they could not solve the problem within the experiment time, they asked for 5 min more to finish the problem solving.

Table 5 shows the number of visual and verbal messages that each dyad generated during the experiment, as well as the time each dyad spent on the problem as well. 
Table 5

Time spent and number of verbal and visual messages for all eight problems.

\begin{tabular}{|c|c|c|c|c|c|c|c|c|c|c|}
\hline & & P.1 & P.2 & P.3 & P.4 & P.5 & P.6 & P.7 & P.8 & Total \\
\hline \multirow[t]{4}{*}{ Henry-Peter (male-male) } & Duration & $25: 34$ & 19:36 & $23: 13$ & $18: 45$ & $16: 43$ & $18: 57$ & $27: 44$ & $23: 34$ & 172:06 \\
\hline & Visual & 27 & 28 & 33 & 22 & 24 & 29 & 37 & 32 & 232 \\
\hline & Verbal & 80 & 65 & 84 & 54 & 57 & 72 & 54 & 73 & 539 \\
\hline & Total & 107 & 93 & 117 & 76 & 81 & 101 & 91 & 105 & 771 \\
\hline \multirow[t]{4}{*}{ Sandy-Carol (female-female) } & Duration & 39:07 & $26: 47$ & $20: 30$ & $35: 35$ & $47: 16$ & 30:04 & $31: 32$ & $35: 45$ & 265.16 \\
\hline & Visual & 21 & 13 & 17 & 14 & 32 & 23 & 28 & 24 & 172 \\
\hline & Verbal & 130 & 96 & 93 & 113 & 153 & 132 & 149 & 109 & 975 \\
\hline & Total & 151 & 109 & 110 & 127 & 185 & 155 & 177 & 133 & 1147 \\
\hline \multirow[t]{4}{*}{ Jenny-Ralf (mixed-gender) } & Duration & $1: 05: 18$ & $45: 48$ & $47: 43$ & $38: 42$ & $54: 25$ & $50: 35$ & $48: 37$ & $57: 49$ & 406.97 \\
\hline & Visual & 54 & 27 & 36 & 24 & 48 & 37 & 39 & 36 & 301 \\
\hline & Verbal & 150 & 148 & 156 & 106 & 146 & 120 & 157 & 107 & 1090 \\
\hline & Total & 204 & 175 & 192 & 130 & 194 & 157 & 196 & 143 & 1391 \\
\hline
\end{tabular}

We found that the Jenny-Ralf dyad spent the most time on the tasks, 406.97 min in total whereas the Henry-Peter dyad spent the least time, $172.06 \mathrm{~min}$. The Jenny-Ralf dyad also produced the most messages during their collaboration; 1391 pieces of verbal and visual exchanges during the process of solving eight problems. Sandy-Carol generated 1147 pieces of exchanges. It was interesting to notice that Henry-Peter dyad generated the least verbal messages than did the Sandy-Carol and Jenny-Ralf dyads, but they exchanged a great many visual messages, around 232.

\subsection{Joint and individual knowledge elaboration}

Next, we will take the space explorer problem as an example in order to visualize students' joint and individual knowledge elaboration. In this problem, students tended to make two mistakes: either they took the gravity acceleration for granted or mixed the maximal speed and the constant speed.

\subsection{Case 1: Henry-Peter dyad}

Henry and Peter spent 19"07' in total on the problem. They submitted their answers twice, at 11"51 and 19"07', respectively.

Adding up all their elaboration values, we arrived at the joint knowledge elaboration curve (on the left in Fig. 2). We found that the majority of the time the elaboration curve rose, which indicated that the dyad was engaged in joint knowledge elaboration. Only at the later stage of the collaboration did boys appear to talk about something off-task, and the curve then dropped. But later it seemed that they returned to the topic. This was reflected in the fluctuating tail of their joint elaboration curve.

We then added up the elaboration values for the individuals and plotted the sum (on the right in Fig. 2). We found that the curves were entangled with each other for most of the time. During the first $13 \mathrm{~min}$, there was no substantial gap between the elaboration curves. It was hard to say whether one participant was elaborating more than the other. This would indicate that Henry and Peter contributed to the final solution in turns.

We will now take a closer look at the process by which Henry and Peter discovered their misconceptions and elaborated their knowledge incrementally. The following excerpt (see Appendix 1) about the acceleration documented all the interactions from 3:59 to 8:01.
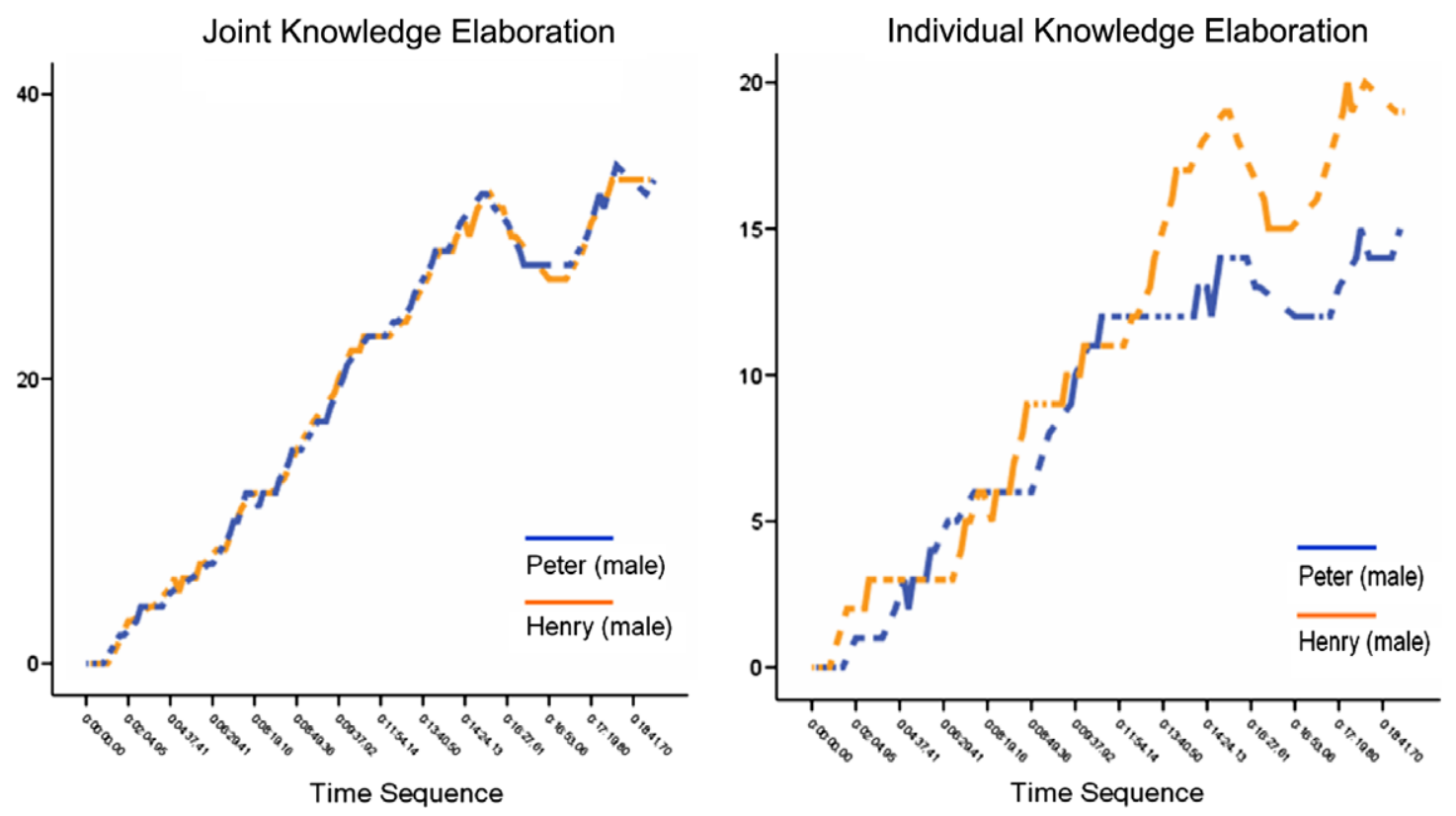

Fig. 2. The joint and individual knowledge elaboration by Henry and Peter. 
The column "Value" shows the elaboration value of each message, ranging from -1 to +1 . The column "Joint value" shows the sum of "Value". In this case, Henry and Peter earned six points during the 4-min collaboration. The numbers in the "Individual value" column were the sums of the individual "Value." For example, two of Henry's messages had a "+1" during the 4-min interaction. He received two points during this period. In contrast, four of Peter's messages had a " +1 ” point and he received four points.

\subsubsection{Cross knowledge elaboration}

Within the 4-min communication Henry and Peter exchanged eighteen pieces of text-based messages in order to find the acceleration. From reading the first nine messages, one might be impressed at the important role Henry was playing. He proposed starting with acceleration, then using the equation and gravity acceleration. Peter looked like a follower, working under Henry's guidance. Until 05:56 we could not tell whether Peter was cognitively engaged in collaboration or not.

The turning point happened at 05:56.9. At that time, the individual cognitive difference appeared. This triggered the subsequent argumentation. Peter corrected Henry's proposal and pointed out his misconception. There was a communicative incoherence from 05:56 to 06:13. It appeared that Peter was engaged in typing his arguments while Henry continued with his approach. But the incoherence was not serious because Peter still successfully used his argument to clarify the points. In the following collaboration, Peter guided Henry towards the correct way of solving the problem. Finally, they found the acceleration together.

From Peter's argumentation we found that his previous words were not indicative of a "free-ride." He was keeping a close eye on his partner's processing. They took turns dominating the knowledge elaboration. From the individual elaboration process, it was hard to find a salient difference between Henry and Peter. Both of the participants pushed the process of problem solving and knowledge elaboration. Their individual knowledge elaboration curves looked more like two crossed curves. Consequently, we named such a pattern a "cross knowledge elaboration". We acknowledged the individual difference in joint knowledge elaboration. Some differences might be due to the initial cognitive difference that the participants brought to the collaboration; others might result from the communication incoherence of CSCL. We found that mechanisms like argumentation contributed to both joint and individual knowledge elaboration.

\subsection{Case 2: Sandy-Carol dyad}

Sandy and Carol spent 15"34' on the problem. At 14"07' they attempted to answer for the first time, and at 15"34' for the second time. They also only correctly solved the force, failing with the maximum height.

From the illustration of their joint knowledge elaboration (on the left in Fig. 3), we found that the girls barely talked to each other about anything off-track during their problem solving. However, during the last stage of the problem solving, it seemed that they reached a plateau where there was no further advancement of knowledge elaboration.

After plotting the sum of Sandy and Carol's values, respectively, we were able to visualize the individual elaboration process (on the right in Fig. 3). We found that there was a substantial gap between the girls. Sandy seemed to excel Carol in knowledge elaboration and guided her from beginning to end. But we also noticed that the curves stayed roughly parallel to each other. It looked like that Carol was following closely all the time, but without widening the gap between them. The detailed elaboration values can be found in Appendix 2 .

\subsubsection{Parallel knowledge elaboration}

When we looked at the overall individual elaboration curves, we were impressed by the gap between Sandy and Carol. The difference between their individual elaborations was clearly addressed. Sandy seemed to play a dominant role, and most of the time she achieved a higher elaboration level than did Carol. But it is also worth noting that the knowledge elaboration curves remained roughly parallel until the end of the collaboration. This was defined as a "parallel knowledge elaboration" pattern.
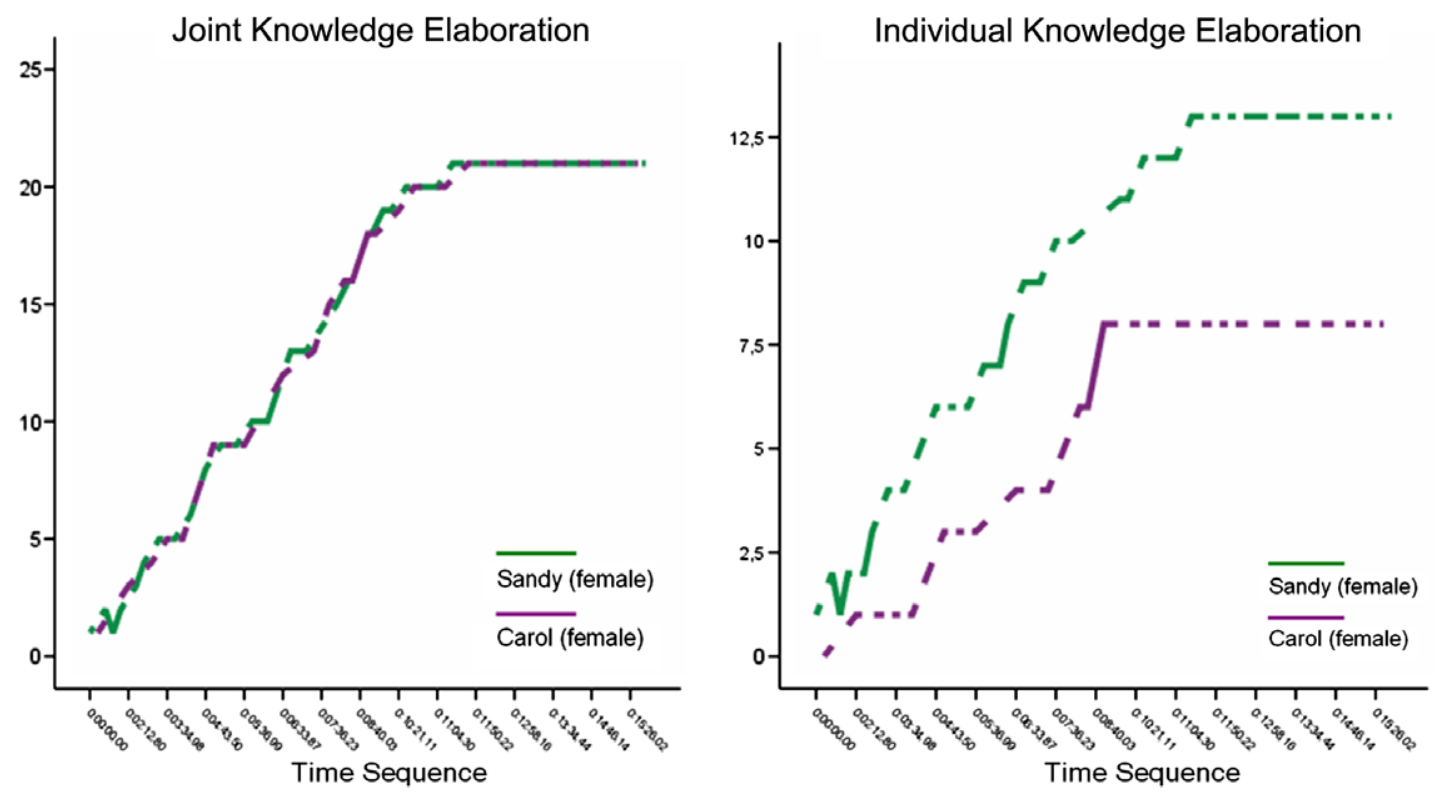

Fig. 3. The joint and individual knowledge elaboration by Sandy and Carol. 
When we zoomed in on one of their problem-solving episodes, we found one key feature that contributed to the parallel knowledge elaboration between the girls. That was explanation. Once they encountered a cognitive difference, Sandy's explanations helped the dyads reach an understanding.

Among the 24 messages, Carol used a question mark nine times. Some of the questions played an important role in keeping up with her partner's knowledge elaboration. Most of Sandy's messages hinged around Carol's questions. At 06:03 when Sandy pointed out her misinterpretation, Carol asked “then?". This question triggered Sandy's concrete solving strategy. While Sandy was recalling the relevant equations, Carol also asked two questions. From her question we knew that she was keeping a close eye on Sandy's progress. Once Sandy came up against the barrier, Carol proposed her own idea, "Is $a$ the $g$ ?" (Line 13). The reason that she used a question mark might be due to her lack of confidence. When Sandy's explanation was ambiguous and haphazard, Carol questioned her closely (Line 16), asking for a full and reasonable explanation. Another important question by Carol was at 10:04 when she became confused at Sandy's abrupt answer (Line 21). She asked about how Sandy got the $5 \mathrm{~m} / \mathrm{s}^{2}$. According to her question, Sandy listed the equation as an explanation, triggering Carol to do further calculation. From the excerpt we found that, based on Carol's questions, Sandy elaborated her explanation more logically. The collaborative problem-solving and knowledge elaboration process was jointly propelled by both of the girls, where Carol was the questioner and Sandy was the respondent.

\subsection{Case 3: Jenny-Ralf dyad}

We will now take a look at how Ralf and Jenny worked on the space explorer problem. In total, Ralf and Jenny spent more than one hour (1'05") on it. They exchanged 369 messages (312 verbal representations and 57 visual representations). Of those, 361 were task-related. Among the 57 visual representations Ralf produced 52 visual representations while Jenny only generated five.

In comparison with the other two dyads, this dyad spent the most time on this problem and exchanged the most messages. From the illustration of their joint knowledge elaboration (on the left in Fig. 4), it was found that the overall elaboration curve rose smoothly, without any sharp drop of off-task talk as what we found in the Henry and Peter dyad. After the dyad reached a plateau, they still furthered their knowledge elaboration and propelled it to a higher level, unlike the Sandy-Carol dyad.

From the perspective of joint knowledge elaboration, this dyad was successful in this problem. However, when we plotted the sum of individual elaboration values (on the right in Fig. 4), we found two divergent curves. Only in the first 5 min were Ralf and Jenny's curves entangled with each other. After that, a gap appeared and the gap tended to become larger and larger.

Based on this, we traced the timeline and circled the time point at which Ralf and Jenny diverged, that is, between 12:51 and 19:07. Then we zoomed in on the conversation to diagnose the crux of the divergent individual elaboration curves. Fig. 5 magnified both their joint (on the left of Fig. 5) and individual elaboration processes (on the right of Fig. 5) from 12:51 to 19:07. The detailed elaboration values can be found in Appendix 3.

\subsubsection{Divergent knowledge elaboration}

We circled the staging area and found there were at least two problems that resulted in the divergent knowledge elaboration.

The first was the incoherence in communication occurring between 15:38 and 16:14. Although we also found some communicative incoherencies in Henry-Peter's and Sandy-Carol's interactions, the one between Jenny and Ralf was especially destructive for Jenny's knowledge elaboration. Jenny tended to hedge or to ask questions while Ralf was more likely to go directly to the calculation. At one point, there was incoherent communication: Jenny was still stuck on the previous question (e.g. Line 16) while Ralf had already switched to the next episode (e.g. Line 17). The gap between Ralf and Jenny's knowledge elaboration was becoming exacerbated.

The second problem was Ralf's no-explanation and Jenny's no-negotiation. There were two turning points caused by Ralf's ignoring of Jenny's questions from 16:54 to 18:30. Firstly, Jenny argued that the speed might be constant (Line 16). She used a question format to put forward her idea, implying that she was not very sure about it. But Ralf ignored her question, declaring that he had found out how
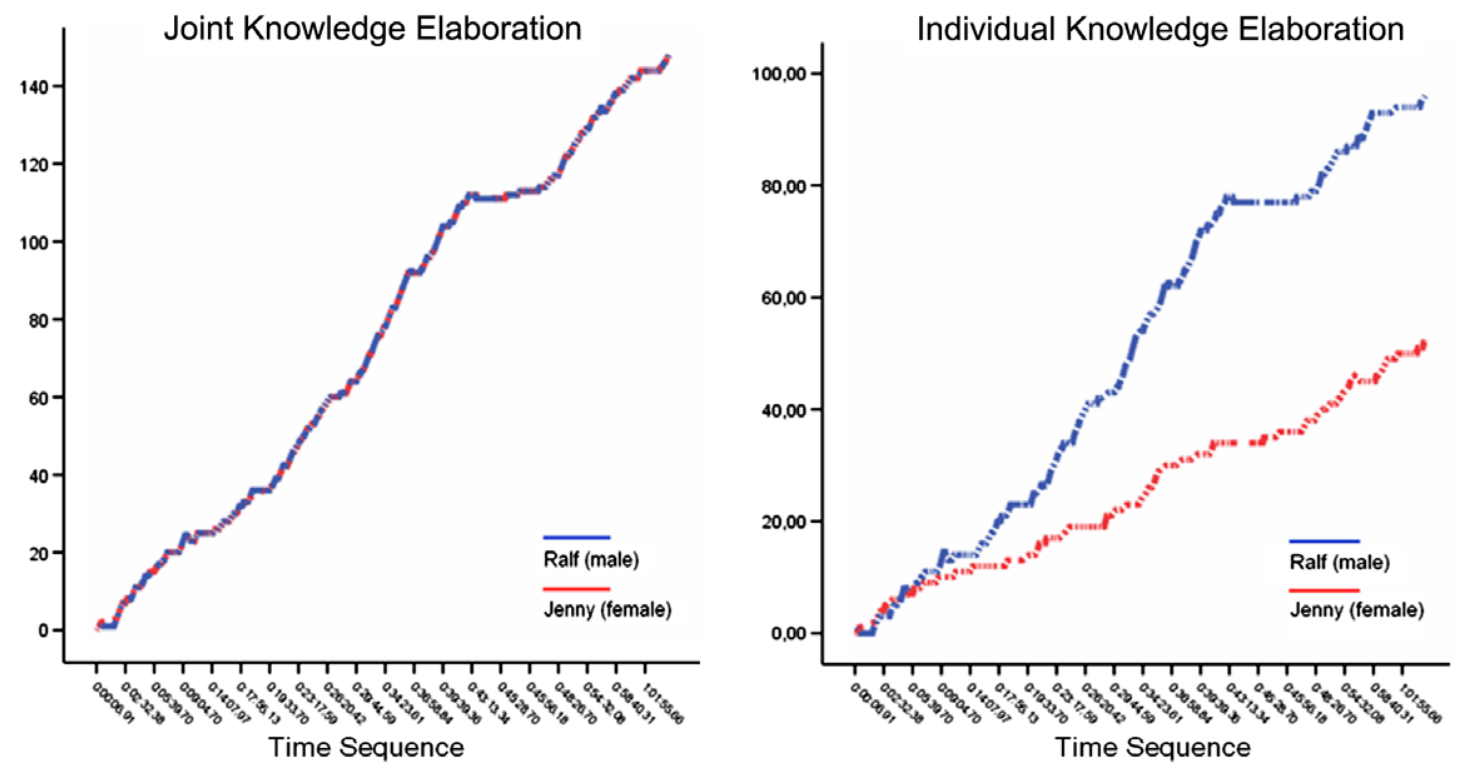

Fig. 4. The joint and individual knowledge elaboration by Ralf and Jenny. 

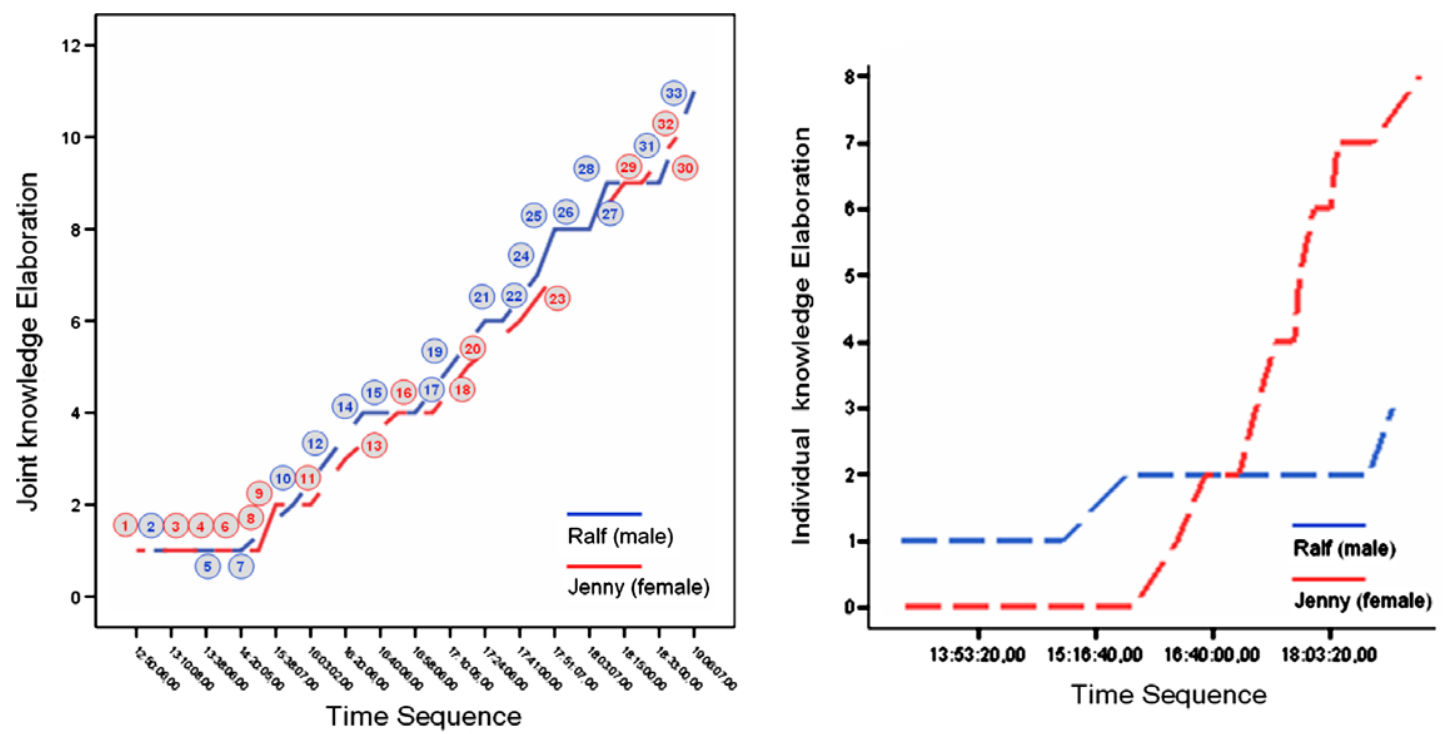

Fig. 5. The joint and individual knowledge elaboration by Ralf and Jenny from 12:51 to 19:07.

Table 6

The individual knowledge elaboration patterns of the three dyads in all problems.

\begin{tabular}{|c|c|c|c|c|c|c|c|c|}
\hline & P.1 & P. 2 & P.3 & P.4 & P.5 & P.6 & P.7 & P.8 \\
\hline Henry-Peter & $\times$ & $\times$ & $<$ & $=$ & $\times$ & $=$ & $=$ & $\times$ \\
\hline Sandy-Carol & $=$ & $=$ & $=$ & $=$ & $\times$ & $\times$ & $\times$ & $\times$ \\
\hline Jenny-Ralf & $<$ & $<$ & $=$ & $<$ & $<$ & $<$ & $=$ & $<$ \\
\hline
\end{tabular}

* $\times$, cross pattern; =, parallel pattern; <, divergent pattern.

to calculate the acceleration (Line 17). Instead of questioning him closely, we found that Jenny also gave up on her question and soon accepted Ralf's suggestion. Next, at 18:15, when Jenny asked how Ralf got the 40/8, she mentioned delta v/delta t (Lines 29 and 30 ). This showed that she was still confused about the speed. But Ralf did not offer her any explanation. Instead, he asked Jenny to do the calculation (Line 31). Jenny followed his instruction and put aside her doubt once again (Line 32). Their collaboration on acceleration ended up with several unsolved questions on Jenny's part. Given the necessity of explanations, Ralf's ignoring and Jenny's stop-asking behavior seemed to be detrimental. Although this dyad generated the most elaborative collaboration, one price paid was Jenny's relatively low-level knowledge elaboration.

\subsection{Summary of case studies}

We collected both students' verbal (text-based chatting) and visual (computer-supported drawings) exchanges and used the elaboration value to explore their knowledge elaboration process. The following table (Table 6 ) summarizes each dyad's individual elaboration patterns across eight experimental problems.

One thing should be noted, when we defined the students' individual elaboration patterns, we focused on the majority of the solving time, and on the major feature that characterized the dyad. For instance, whether the curves became entangled with each other or remained parallel in a divergent pattern, we named this simply a divergent pattern because the dominant feature was two curves diverging from each other.

Generally speaking, it is hard to say that one dyad stuck to one pattern all the time. For example, in the Henry-Peter dyad, the individual knowledge elaboration patterns were more or less mixed. However, it was worth noting that there was no divergent pattern in the SandyCarol dyad whereas there was no cross pattern in the Jenny-Ralf dyad. Furthermore, within all the divergent patterns in the Jenny-Ralf dyad, Ralf's curve always stayed above Jenny's.

\section{Conclusion and discussion}

When we looked into the content of students' interactions through the lens of knowledge elaboration, we found three unique patterns of individual knowledge elaboration: cross knowledge elaboration with two crossed elaboration curves; parallel knowledge elaboration with two almost parallel elaboration curves; and divergent knowledge elaboration with two deviating elaboration curves.

In the cross elaboration pattern, we found two mechanisms: cognitive difference and argumentation. Once Henry found that he had a different idea to Peter, he addressed the difference directly and used an argument to support himself. Although there was one instance of communicative incoherence, their discussion still went well and both participants reached an understanding. However, the Henry-Peter dyad had the most mixed elaboration patterns and they solved fewer problems in comparison than the other dyads. In this dyad, we found a large amount of off-task talk and low-level routine discussions without constructive thinking. The computer facilitated their 
communication and co-construction of knowledge, but sometimes they worked on the problem too rashly because it was too convenient to submit and check their answers.

In the parallel elaboration pattern, mechanisms such as cognitive difference and explanation were found. While Henry had a different problem-solving approach to Peter, Carol had not even conceived of a concrete approach yet. She used several short and simple questions revealing what she did not know. Responding to her questions, Sandy explained step by step, although some explanations appeared to be rather simple and haphazard. There also were incoherencies in communication. Still, their interaction was generally effective. However, in line with our previous findings (2006) that female students' tend to express their ideas verbally, in the Sandy-Carol dyad we found the least amount of visual representations. In the physics problem-solving tasks, many geometric concepts such as schemas or graphs can express myriad words in economical form. A lack of visual representation runs the risk of curtailing problem-solving effectiveness.

For the Ralf-Jenny dyad, the divergent elaboration pattern was dominant. However, the dyad was productive, since we took the group as a unit of analysis. From Table 6, we knew that the mixed-gender dyad, the Jenny-Ralf dyad, seemed to be the most productive dyad. They solved the most problems, exchanged the most visual and verbal messages and spent the most time on problem-solving tasks during the experiment. However, this came at the cost of a deviation in Jenny's individual knowledge elaboration. The mechanisms that resulted in the divergent individual elaboration were Ralf's ignoring-questions and Jenny's stop-asking activities. In a computer-mediated distance learning setting, the lack of a shared context and co-present cues may inhibit students' communication and knowledge elaboration (Stahl, 2006), at least as far as the individual knowledge elaboration is concerned.

Our case study has the potential to shed light on research on collaborative learning as a group process versus an individual process, which is "a tension at the heart of CSCL" (Stahl et al., 2006). First, we took a "close-up" view of the process involved in the students' cognitive elaborations. We were interested in questions such as how they responded to their partner's message, how they process the received information cognitively, how they elaborate the knowledge jointly and individually, and what the difference was between joint and individual knowledge elaboration. Second, we used the elaboration values to evaluate each message and visualize the process of elaboration by plotting the values along a timeline. Such visualizations offered us a direct impression of the difference between the different dyads and the difference between the participants within a dyad. Third, we differentiated the joint cognitive activity from individual cognitive activities. Doing so helped us explain the dilemma of one group succeeding at the cost of one of the individuals.

Still, there are two points that should be pointed out. First, more patterns or more mechanisms may have been revealed if we had involved more dyads in the study. Secondly, it is hard to say that one pattern excelled the others. It depended largely on whether we took the group or the individual as a unit of analysis.

Due to the limited number of participants, we were also unable to correlate the elaboration patterns with the learning performance through CSCL as well. However, our microscopic analysis of the Ralf-Jenny dyad indicated why one student was put at a disadvantage while the group succeeded. Even if consensus was reached, there was always the possibility that one student might revert to no cognitive involvement. In our future research, we will be investigating whether female students' are generally at a disadvantage in terms of individual knowledge elaboration, and we will explore whether the patterns are statistically related to students' learning performances.

\section{Appendix A. Supplementary material}

Supplementary data associated with this article can be found, in the online version, at doi:10.1016/j.compedu.2008.10.009.

\section{References}

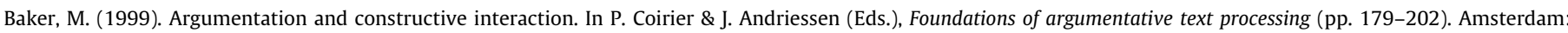
Amsterdam University Press.

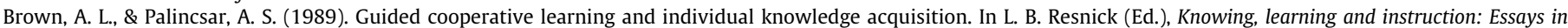
honor of Robert Glaser (pp. 395-451). Hillsdale, NJ: Lawrence Erlbaum.

Chang, K. E., Sung, Y. T., \& Lee, C. L. (2003). Web-based collaborative inquiry learning. Journal of Computer Assisted Learning, 19(1), 56-69.

Cohen, E. G. (1994). Restructuring the classroom: Conditions for productive small groups. Review of Educational Research, 64(1), 1-35.

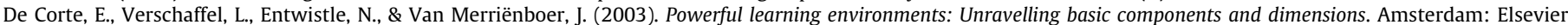
Science.

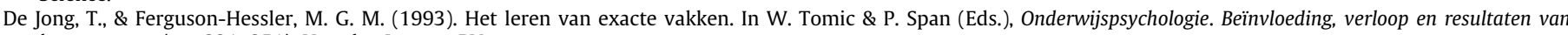
leerprocessen (pp. 331-351). Utrecht: Lemma BV.

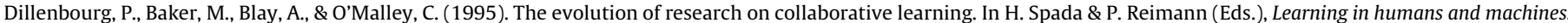
Towards an interdisciplinary learning science (pp. 189-211). Oxford: Pergamon.

Dillenbourg, P. (Ed.). (1999). Collaborative learning: Cognitive and computational approaches. Amsterdam: Pergamon, Elsevier.

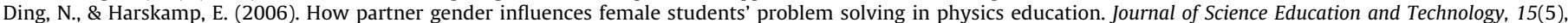
331-343.

Dix, A., Finlay, J., Abowd, G., \& Beale, R. (1998). Human-computer interaction (2nd ed.).

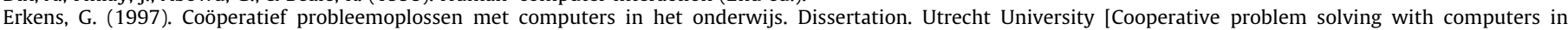
education].

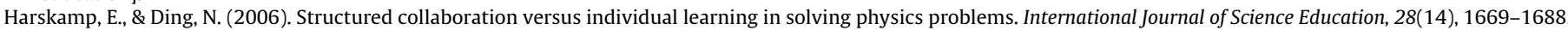
Heller, P., Keith, R., \& Anderson, S. (1992). Teaching problem solving through cooperative grouping. American Association of Physics Teachers, 60(7), 627-636.

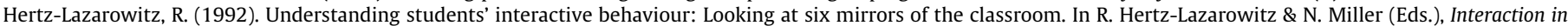
cooperative groups: The anatomy of group learning (pp. 71-102). New York: Cambridge Press.

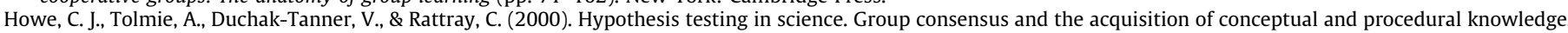
Learning and Instruction, 10, 361-391.

Johnson, D. W., \& Johnson, R. T. (1994). Learning together and alone: Cooperative, competitive, and individualistic learning (4th ed.). Boston, MA: Allyn and Bacon.

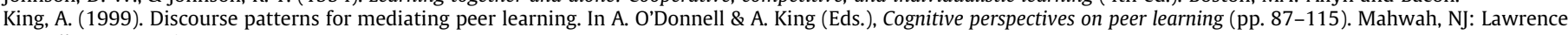
Erlbaum Associates.

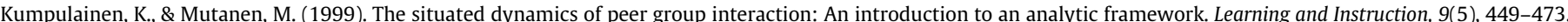

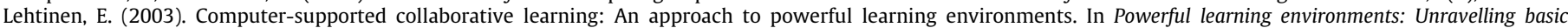
components and dimensions (pp. 35-53). Pergamon.

Lemke, J. L. (1990). Talking science: Language, learning and values. Norwood, NJ: Ablex.

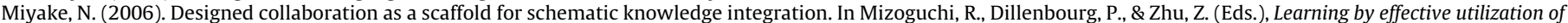
technologies facilitating intercultural understanding. Proceeding of international conference on computers in education (ICCE 2006) (pp. 15-20). Beijing, China. 


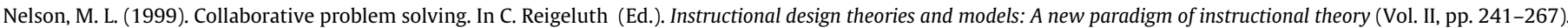
Mahwah, NJ: Lawrence Erlbaum Associates Inc..

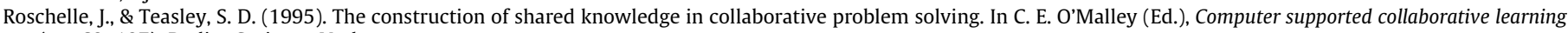
(pp. 69-197). Berlin: Springer-Verlag.

Sizmur, S., \& Osborne, J. (1997). Learning processes and collaborative concept mapping. International Journal of Science Education, $19(10), 1117-1135$.

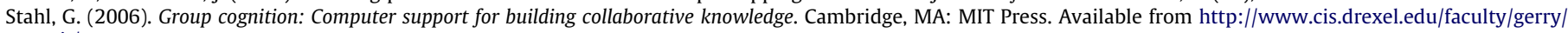
$\mathrm{mit} /$.

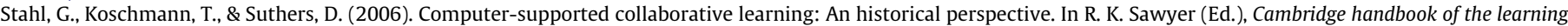
sciences. Cambridge, UK: Cambridge University Press.

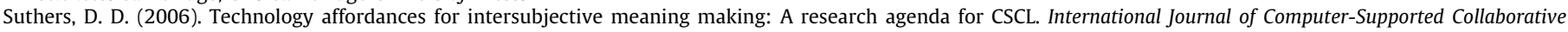
Learning, 1(3), 315-337.

Teasley, S. (1995). The role of talk in children's peer collaboration. Developmental Psychology, 3(2), 207-220.

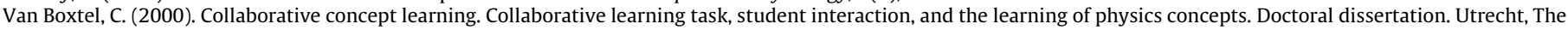
Netherlands: Print Partners Ipskamp.

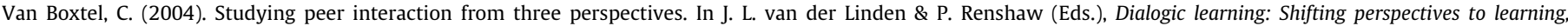
instruction, and teaching (pp. 125-143). Dordrecht: Kluwer.

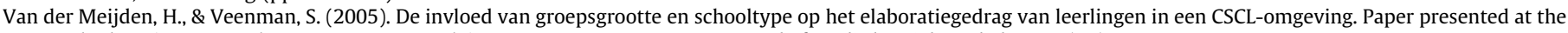
32nd Education Research Day 2005, Gent, Belgium, 30 May-1 June, 2005. Journal of Applied Social Psychology, 28(22), $2049-2067$.

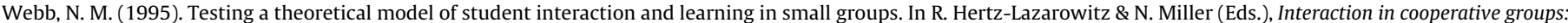
The theoretical anatomy of group learning. NY: Cambridge University Press.

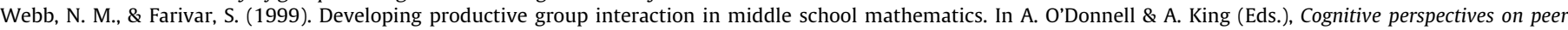
learning (pp. 117-149). Mahwah, NJ: Lawrence Erlbaum Associates. 